\title{
Discussion on banning advertising of cosmetic surgery needs to consider medical tourists
}

\author{
Johanna Hanefeld lecturer in health systems economics ${ }^{1}$, Neil Lunt senior lecturer in social policy \\ and public management ${ }^{2}$, Daniel Horsfall lecturer in comparative social policy ${ }^{2}$, Richard Smith \\ professor of health system economics, and dean ${ }^{1}$
}

${ }^{1}$ Faculty of Public Health and Policy, London School of Hygiene and Tropical Medicine, London WC1H 9SH, UK; ${ }^{2}$ University of York, York, UK

The discussion on banning advertising of cosmetic surgery neglects an important aspect of safeguarding UK consumers from direct marketing by cosmetic surgery providers to the public $^{1}$ : an increasing number of UK patients travel abroad for cosmetic surgery.

In 2010, 63000 UK residents travelled to access treatment abroad. ${ }^{2}$ Our research indicates that around 30\% (18 300) of them were cosmetic tourists. This echoes the results of a survey conducted by Which? magazine: $28 \%$ of medical tourists travelled for cosmetic procedures. ${ }^{3}$ This is likely to be a growing trend: $97 \%$ of people considering cosmetic surgery would consider travelling for it. ${ }^{4}$

Our research shows that most patients identify and choose foreign providers through the internet. This underlines the necessity to extend considerations to the internet and specifically medical tourists. We found that patients who travelled for cosmetic treatment are unlikely to consult their general practitioner out of fear of being judged. There is thus greater urgency for accessible information and guidance for those considering travelling abroad for cosmetic surgery.

A ban on advertising by UK providers will address some of the concerns raised by the recent PIP scandal, as might regulation of advertising if enforcement measures are in place. However, a comprehensive review of cosmetic surgery needs to consider the increasing number of patients travelling abroad for cosmetic procedures or risk that its recommendations are little more than a short term fix.

Competing interests: None declared.

The authors have recently completed a two year research project on UK medical tourism funded by the National Institute for Health Research (NIHR). This included interviews with UK residents who had travelled abroad to access cosmetic surgery.

Godlee F. Promoting cosmetic surgery [Editor's choice]. BMJ 2012;345:e7535. (8 November.)

Smith R, Lunt N, Hanefeld J. The implications of PIP are more than just cosmetic. Lancet 2012;379:1180-1.

3 Which? We expose medical tourism pitfalls. Which?2008 Mar 20. www.which.co.uk/news/ 2008/03/we-expose-medical-tourism-pitfalls-135137/.

4 Nassab R, Hamnett N, Nelson K, Kaur S, Greensill B, Dhital S, et al. Cosmetic tourism: public opinion and analysis of information and content available on the Internet. Aesthetic Surg J 2010;30:465-9.

Cite this as: BMJ 2012;345:e7997

๑ BMJ Publishing Group Ltd 2012 